\title{
Análise quali-quantitativa de formaldeído em amostras de produtos destinados ao alisamento capilar utilizados em salões de beleza no município de Linhares, ES - Brasil
}

\author{
Qualitative and quantitative analysis of formaldehyde in samples of \\ products for hair straightening used in salons of Linhares, ES - Brazil
}

Recebido em: 05/12/2014

Aceito em: 05/01/2015

Valdinara de Oliveira CRIPPA, Lo Ruama Freitas TEIXEIRA,

Luciana Camizão REBELLO

Faculdade Pitágoras. Avenida São Mateus, 1458, Araçá, Linhares, ES, CEP: 29901-398, Brasil.E-mail: valdinara_crippa@hotmail.com

\section{ABSTRACT}

Formaldehyde provides greater durability and effectiveness in hair straightening processes, and with these purposes, became commonly used irregularly. With Brazilian law, RDC n 79, 2000 (Anvisa), the use of formaldehyde in cosmetics is allowed in maximum $0.2 \%$ concentration, exclusively for conservation. Because it is a substance that can cause small irritation to carcinogenesis, the aim of this study was to check whether the main hair straighteners used in Linhares, ES - Brazil are meeting the specifications required by applicable law. Ten samples of different brands were collected and based on the Guide to Quality Control of Cosmetic Products of ANVISA realized qualitative analysis through identification with the Schiff reagent and dosing done by reaction with acetylacetone. Of the ten products tested, all showed formaldehyde and $80 \%$ had levels above permitted. These results indicate the need for strict and constant control of hair straighteners marketed and awareness strategies about the risks of use of formaldehyde.

Keywords: formaldehyde; hair straightening; toxicity; occupational hazard

\section{RESUMO}

O formaldeído proporciona maior durabilidade e efetividade em processos de alisamento capilar, e então, passou a ser comumente usado de forma irregular para esse fim. Com a RDC $\mathrm{n}^{\circ} 79$ de 2000, da Anvisa, o uso de formaldeído passou a ser permitido em concentração máxima de $0,2 \%$ nos produtos cosméticos, com a finalidade de conservação. Por se tratar de uma substância que pode causar desde uma pequena irritação até carcinogênese, o objetivo deste trabalho foi verificar se os principais alisantes capilares utilizados no município de Linhares, ES - Brasil estavam cumprindo as especificações exigidas pela legislação vigente. Foram coletadas dez amostras de marcas diferentes e, com base no Guia de Controle de Qualidade de Produtos Cosméticos da ANVISA, realizada a análise qualitativa por identificação com o reagente de Schiff e feito o doseamento por reação de acetilacetona. Dos dez produtos analisados, todos apresentaram formaldeído e $80 \%$ estavam com níveis acima do permitido. Estes resultados indicam que há necessidade de uma fiscalização mais rígida e constante dos alisantes capilares comercializados e estratégias de sensibilização sobre riscos de utilização do formol.

Palavras chave: formol; alisante capilar; toxicidade; risco ocupacional 
INTRODUÇÃO

Os cuidados com a beleza são uma realidade na atualidade, seja pela influência da mídia, seja pela busca da satisfação pessoal a partir da conquista de uma aparência desejada, por exemplo, o desejo pelos cabelos lisos por parte das mulheres contemporâneas. Aliado a isso, pode ser observado o crescimento do mercado cosmético mundial, no qual o Brasil ocupa a terceira posição, sendo o segundo do ranking em produtos destinados aos cabelos (1).

Nessa demanda, encontram-se os alisantes capilares, que podem ser apresentados também com a denominação de amaciantes, relaxantes e desfrizantes, utilizados nas técnicas de alisamento profissional - denominadas de escova progressiva, escova definitiva, escova inteligente, entre outras - que tem por objetivo alterar temporariamente a estrutura dos cabelos para obtenção de uma forma mais lisa dos fios (2).

As substâncias ativas dos produtos para alisamento capilar agem diretamente sobre a estrutura do fio de cabelo, mais precisamente na região do córtex, rompendo as ligações dissulfídicas, tornando a fibra momentaneamente deformável e sem elasticidade, que em seguida são fixadas na forma desejada pela reconstrução dessas ligações por aplicação de um agente neutralizante, realocando a queratina dentro do córtex e reorganizando as escamas da cutícula capilar, selando o fio de cabelo, fazendo com que adquira o formato liso de forma duradoura $(3,4)$.

Os agentes alisantes autorizados pela Anvisa e comumente utilizados são o tioglicolato de amônio e os hidróxidos de sódio, hidróxido de potássio, hidróxido de cálcio, hidróxido de lítio e guanidina (5).

De forma irregular, o formaldeído passou a ser empregado para propiciar maior durabilidade e efetividade ao processo de alisamento, uma vez que este utiliza das ligações dissulfídicas já rompidas para formar uma ligação metilênica que modifica a conformação das microfibrilas que compõem o córtex capilar, proporcionando maior alisamento da fibra, gerando também um alinhamento das cutículas fornecendo aos fios um aspecto brilhante (2).

Desde 2000, com a publicação RDC n ${ }^{\circ} 79$ e suas atualizações com a RDC 162/2001 e RDC 215/2005, o uso de formaldeído somente é permitido em produtos cosméticos como conservante, tendo sua concentração máxima de apenas $0,2 \%$, exceto para endurecedores de unhas que é de até $5 \%$; devendo ainda estar advertido no rótulo dos produtos que possuem um valor superior a $0,05 \%$ de formaldeído na sua concentração final a informação: contém formaldeído (5-7).
O uso de formaldeído em concentrações acima do permitido, bem como seu acréscimo a produto acabado, constitui infração sanitária, conforme estabelecido pela Lei ${ }^{\circ}$ 6.437/1977 (8).

Essa utilização indevida pode provocar graves danos à saúde, tanto para o usuário, quanto para os profissionais que aplicam o produto, sendo este risco proporcional à concentração e frequência de uso, devido à ação irritante principalmente sobre o aparelho respiratório superior e mucosas dos olhos, e ainda, sendo potencial agente cancerígeno, com base na evidência de que a exposição prolongada é susceptível de causar carcinoma nasofaríngeo (9-11).

Visto a necessidade de coibir o uso indiscriminado de formaldeído associado ou adicionado a produtos capilares com finalidade de alisamento, foi emitida outra resolução, a RDC n ${ }^{\circ} 36$, de 17 de julho de 2009, que proíbe a venda de formaldeído (solução a 37\%) em farmácias, drogarias, supermercados, armazéns e lojas de conveniências, reduzindo, deste modo, a facilidade na compra dessa substância (12).

Porém, mesmo com essas regulamentações, a probabilidade do uso irregular de formaldeído em alisantes capilares ainda é considerável, pela garantia do efeito liso e brilhante de forma rápida que esse ativo proporciona, além de ser um produto barato (3). Sendo assim, são desconsiderados os danos que seu uso pode causar tanto para os cabelos, que ficam mais frágeis, quebradiços e desidratados, quanto ao usuário final em função dos sérios riscos de intoxicação por inalação e contato com a pele, bem como para os profissionais que aplicam o produto (13).

Algumas análises realizadas por pesquisadores em amostras de produtos destinados ao alisamento capilar obtidas em salões de beleza entre os anos de 2003 a 2013 confirmaram esse uso irregular, apresentando resultados com teor de formaldeído muito acima do limite máximo permitido (14-19). Isso mostra que, mesmo com os riscos de toxicidade e limitações definidas pela Anvisa, os problemas com relação ao uso de formaldeído de forma indevida em alisantes capilares ainda são reais, demonstrando possível falta de controle no processo de produção ou envase, ou ainda adulteração pós venda (20).

Diante desses fatos, o presente trabalho teve por objetivo verificar a situação dos principais alisantes capilares utilizados em salões de beleza do município de Linhares, ES - Brasil, quanto à presença e concentração de formaldeído. 


\section{MÉTODO}

\section{Amostras}

Dos 139 salões de beleza registrados na Vigilância Sanitária do município de Linhares, ES, foram selecionados aleatoriamente a quantidade amostral de 103 salões, onde, por meio de contato telefônico, foram pesquisadas as marcas de produtos destinados ao alisamento capilar utilizadas por estes, sendo então selecionadas as 10 marcas com maior utilização. Posteriormente, as amostras de cada marca fornecidas gentilmente pelos proprietários dos salões foram coletadas em alíquotas com aproximadamente $15 \mathrm{~g}$ e submetidas à análise qualitativa e quantitativa de formaldeído em triplicata, utilizando os métodos de identificação e doseamento definidos pelo Guia de Controle de Qualidade de Produtos Cosméticos da Anvisa $(21,22)$.

\section{Análise qualitativa}

Para a realização do ensaio de identificação de formaldeído, foram pesados $2 \mathrm{~g}$ da amostra de alisante capilar, transferidos para um béquer de $10 \mathrm{~mL}$ e adicionados de duas gotas de acido sulfúrico $1 \mathrm{M}$ e $2 \mathrm{~mL}$ de reagente de Schiff, sendo a identificação do formaldeído em uma concentração superior a $0,01 \%$ comprovada pelo surgimento de uma coloração rosa ou malva $(21,22)$.

\section{Análise quantitativa}

O doseamento de formaldeído nas amostras que se mostraram positivas na análise qualitativa foi realizado pelo método de reação do formaldeído com acetilacetona em presença de acetato de amônio, formando a 3,5-diacetil-1,4-diiidrolutidina (DDL), extraída com 1-butanol e determinada a absorbância em espectrofotômetro a $410 \mathrm{~nm}$, lida sob uma curva de calibração previamente preparada a partir de solução padronizada de formaldeído (Figura 1), obtendo a quantidade de formaldeído contido em cada amostra, expressa em microgramas, sendo então calculado o teor de formaldeído em porcentagem segundo a fórmula:

$$
\text { Onde: } \begin{aligned}
C= & \text { concentração de formaldeído }(\%) \\
C= & \text { quantidade de formaldeído obtido a partir } \\
& \text { da curva analítica, em } \mu \mathrm{g} \\
\mathrm{m}= & \text { massa da amostra da tomada de ensaio, } \\
& \text { em gramas }(21,22) .
\end{aligned}
$$

\section{RESULTADOS E DISCUSSÃO}

Dos 103 salões contatados, 17 não realizavam procedimentos de alisamento e 14 não quiseram informar quais marcas utilizam. Dessa forma, foi registrado um total de 43 marcas de alisantes capilares, das quais as 10 mais utilizadas foram selecionadas e classificadas de $\mathrm{A}$ a J em ordem decrescente de utilização (Figura 2).

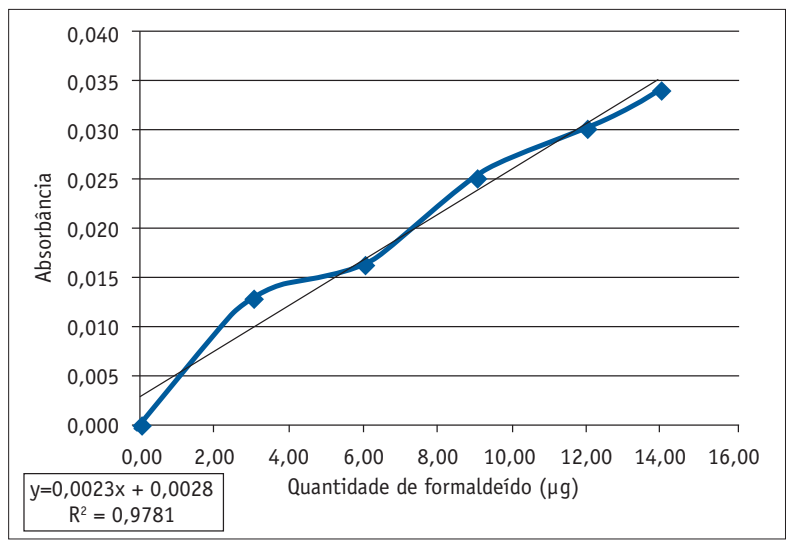

Figura 1: Curva de calibração de solução padronizada de formaldeído

Ao serem submetidas à análise qualitativa, todas as amostras apresentaram resultado positivo, ou seja, presença de formaldeído em quantidade superior a $0,01 \%$.

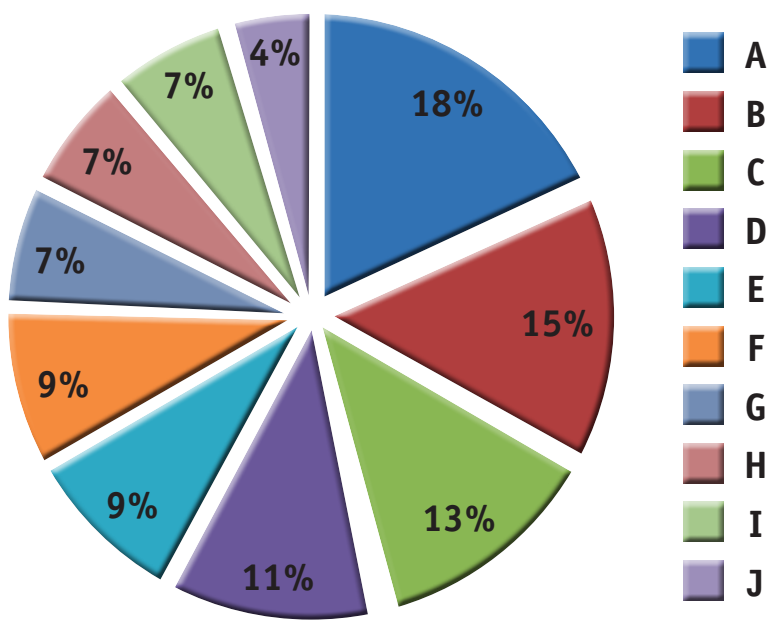

Figura 2 - Percentual de salões que utilizam as marcas de alisantes capilares mais encontrados no município de Linhares, ES.

Da análise quantitativa, apenas 2 amostras (Marca E e H) apresentaram teor de formaldeído abaixo do valor máximo permitido e as demais exibiram valores acima do permitido pela Anvisa, conforme pode ser observado na Tabela 1 .

\section{DISCUSSÃO}

Diante dos resultados obtidos pôde ser observado que mesmo com as legislações vigentes que limitam a utilização de formaldeído em produtos cosméticos, seu uso irregular em alisantes capilares ainda persiste, e em teor muito acima do permitido. 
Percentuais semelhantes foram encontrados por Santa Bárbara e Miyamaru (2008), no período de 2003 a 2007, que relacionaram essas irregularidades à falta de controle na fabricação, e ainda afirmavam terem sido frequentes as ocorrências de denúncias feitas por consumidores que relataram reações adversas ocasionadas pelo uso do produto, demonstrando a implicação dessas irregularidades sobre a saúde de consumidores e profissionais expostos a estes produtos (16).

Tabela 1 - Percentual de formaldeído nos diferentes alisantes capilares e suas respectivas substancias ativas descritas no rótulo do produto.

\begin{tabular}{clrr} 
Amostra & Substancia ativa descrita no rótulo & Teor de formaldeído encontrado & DP \\
A & Arginina & $10,4 \%$ & $\pm 1,4$ \\
B & Arginina & $18,5 \%$ & $\pm 0,6$ \\
C & Células-tronco de maçã & $2 \%$ & \pm 1 \\
D & Guanidina & $8,5 \%$ & $\pm 1,2$ \\
E & Carbocisteína & $0,11 \%$ & $\pm 0,04$ \\
F & Ácido glioxílico & $0,5 \%$ & $\pm 0,1$ \\
G & Arginina & $15,9 \%$ & $\pm 1,1$ \\
H & Sericina & $0,04 \%$ & $\pm 0,01$ \\
I & Tioglicolato de amônio & $5,4 \%$ & $\pm 0,8$ \\
J & Arginina & $6,9 \%$ & $\pm 0,7$ \\
\hline
\end{tabular}

DP = Desvio Padrão.

Outros autores que também encontraram altos teores de formaldeído em suas análises nos anos de 2008, 2012 e 2013, reforçaram o alerta sobre os riscos à saúde com a utilização indevida dessa substância em alisantes capilares e a necessidade de uma fiscalização mais rígida desses produtos, desde a fabricação até sua utilização nos salões de beleza, a fim de coibir o uso do formaldeído em teores acima do permitido no processo produtivo e/ou seu acréscimo pós-venda $(14-16,18,19)$.

Moro e cols. (2013), seguindo os mesmos métodos de ensaio utilizados neste estudo, obtiveram $61,5 \%$ de amostras com percentual de formaldeído acima de $0,2 \%$, contendo, na maioria delas, quantidade dez vezes maior do que o permitido pela legislação. Os autores consideraram que os altos percentuais de formaldeído em alisantes capilares é um problema de saúde pública (15).

Também foi observado que das amostras coletadas no presente estudo, apenas duas continham substâncias ativas autorizadas pela Anvisa como agente alisante, que foram a guanidina e o tioglicolato de amônio. As demais continham substâncias que estão sendo consideradas como substâncias destinadas à proteção e tratamento dos fios e, portanto, sendo classificadas como de baixo risco, registradas então como grau 1 (23), cuja comprovação e informações detalhadas do modo e restrições de uso não são inicialmente necessárias antes de entrar no mercado (24). Com isso, foram verificadas irregularidades, onde os produtos são notificados como simples máscaras hidratantes e redutoras de volume e comercializados com proposta alisante, abrindo margens para o uso irregular de formaldeído nesse tipo de produto.

O uso irregular de formaldeído em alisantes capilares é preocupante para os consumidores, e principalmente, para os que trabalham com esses produtos, pois quanto maior a concentração e frequência de exposição maior é o risco de toxicidade.

Exposições a altas concentrações de formaldeído podem provocar reações adversas significantes, como pôde ser observado em um estudo realizado com 66 indivíduos, sendo eles alunos, professores e trabalhadores do departamento de Anatomia Humana da faculdade de Medicina da Universidade de Los Andes, funcionários do necrotério de ciências policiais e de funerárias da região de Mérida, na Venezuela, com exposição crônica ao formaldeído, observou que em tempo de exposição de 8 a 72 horas por semana foram frequentes os relatos de irritação e obstrução nasal, dor de garganta, tosse seca, dispneia, dor de cabeça, fadiga, diminuição da memória recente, irritação nos olhos e lacrimejamento, além de distúrbios dermatológicos como urticária, bolhas e dermatite (25).

Embora as concentrações de formaldeído em que estão expostos os profissionais de salões de beleza sejam menores, o risco de toxicidade também é considerável, 
como foi observado em análise realizada na Europa, que determinou as concentrações de formaldeído no ar após aplicação dos produtos alisantes com teor de formaldeído acima de $0,2 \%$ no procedimento de alisamento. A concentração média das amostras analisadas foi de $1,46 \%$, obtendo uma média do nível de concentração no ar de $6 \mathrm{ppm}$, ultrapassando assim o nível máximo de segurança definido pela Organização Mundial de Saúde que é de $0,1 \mathrm{ppm}$, sendo evidente a ação irritante sobre as mucosas dos olhos e aparelho respiratório superior (26).

Em relatos de intoxicação de profissionais de salões de beleza do município de Formosa, Goiás, Brasil, por exposição ao formaldeído em alisantes capilares com concentração de $3 \%$, foi observado que os sinais e sintomas mais frequentes foram dores de cabeça, ardência nos olhos, irritação na garganta e enjôos (27).

Nos usuários de alisantes capilares do município de São José dos Pinhais, Paraná, Brasil, foi observado que dentre os sinais e sintomas de intoxicação aguda por exposição ao formaldeído, os que tiveram maior incidência foram, em ordem decrescente, irritação ocular, como ardência e lacrimejamento dos olhos, irritação no nariz, dor de cabeça e descamação do couro cabelo (28).

Diante dos fatos apresentados, alerta-se a importância da necessidade de maior vigilância sobre os produtos cosméticos comercializados e de campanhas educativas direcionadas aos cabeleireiros e consumidores sobre as implicações à saúde que o uso irregular de formaldeído em alisantes capilares pode provocar, bem como estimulá-los a comunicar às agências de vigilância sanitária os possíveis casos de irregularidades, na tentativa de coibir o uso inadequado do formaldeído, reduzindo assim os riscos de exposição.

\section{CONCLUSÃO}

Todos os produtos analisados apresentaram formaldeído e $80 \%$ estavam com níveis acima do permitido. Com base nos resultados apresentados, sugere-se então uma fiscalização mais rigorosa dos alisantes capilares comercializados e o desenvolvimento de estratégias de sensibilização sobre riscos da utilização indevida do formaldeído nesse tipo de produto.

\section{REFERÊNCIAS}

1. ABIHPEC. Associação Brasileira da Indústria de Higiene Pessoal, Perfumaria e Cosméticos. Panorama do Setor. Abril de 2013. Disponível: < http://www.abihpec.org.br/ wp-content/uploads/2013/04/Panorama-do-setor-PORT-05Abr2013.pdf > . Acesso em: 25 de fevereiro de 2014.

2. Franquilino E. Escovas progressivas: mecanismo de ação, opções ao formol e novidades do mercado. Cosmetics \& Toiletries, 2013. 25(25):21-25.

3. Mello MS. A evolução dos tratamentos capilares para ondulações e alisamentos permanentes. [Dissertação]. Porto Alegre: Faculdade de Farmácia, Universidade Federal do Rio Grande do Sul. 2010.

4. Varela AEM. Um estudo sobre os princípios ativos dos produtos para alisamento e relaxamento de cabelos oferecidos atualmente no mercado brasileiro. [Dissertação]. Balneário Camboríu: Tecnologia em Cosmetologia Estética, Universidade do Vale do Itajaí. 2007.

5. BRASIL. Agência Nacional de Vigilância Sanitária. Resolução RDC n ${ }^{\circ} 215$, de 25 de julho de 2005. Aprova o Regulamento Técnico de Listas de Substâncias que os Produtos de Higiene Pessoal, Cosméticos e Perfumes não devem conter, exceto nas condições e com as restrições estabelecidas que consta como anexo e faz parte da presente resolução. Diário Oficial da União. Brasília, 26 jul. 2005 .
6. BRASIL. Agência Nacional de Vigilância Sanitária. Resolução RDC $N^{\circ} 79$, de 28 de agosto de 2000. Lista de Substâncias Permitidas para Produtos de Higiene Pessoal, Cosméticos e Perfumes. Diário Oficial da União. Brasília, 31 ago. 2000.

7. BRASIL. Agência Nacional de Vigilância Sanitária. Resolução RDC n 162, de 11 de setembro de 2001. Estabelece a Lista de Substâncias de Ação Conservantes para Produtos de Higiene Pessoal, Cosméticos e Perfumes. Diário Oficial da União. Brasília, 12 set. 2001.

8. BRASIL. Lei $\mathrm{n}^{\circ} 6.437$, de 20 de agosto de 1977. Configura infrações à legislação sanitária federal, estabelece as sanções respectivas, e dá outras providências. Diário Oficial da União. Brasília, 24 ago. 1977.

9. INCA. Instituto Nacional do Câncer. Formol ou Formaldeído. Disponível: < http://www1.inca.gov.br/conteudo_ view.asp?ID=795>. Acesso em 22 de março de 2014.

10. Viegas SPC. Estudo da exposição profissional a formaldeído em laboratórios hospitalares de anatomia patológica. [Dissertação]. Lisboa: Doutorado em Saúde Pública, Universidade Nova de Lisboa. 2010.

11. IARC-International Agency for Research on Cancer. Monographs on the Evaluation of Carcinogenic Risks to Humans. Formaldehyde. ISBN 9283212886. 2006 . 
12. BRASIL. Agência Nacional de Vigilância Sanitária. Resolução RDC n 36, de 17 de julho de 2009. Dispõe sobre a proibida a exposição, a venda e a entrega ao consumo de formol ou de formaldeído (solução a 37\%) em drogaria, farmácia, supermercado, armazém e empório, loja de conveniência e drugstore. Diário Oficial da União. Brasília, 18 jun. 2009.

13. Abraham LS, Moreira AM, Moura LH, Dias MFRG, Addor FAS. Tratamentos estéticos e cuidados dos cabelos: uma visão médica (parte 2). Surg \& Cosm Derm, 2009. 1(4):178-187.

14. Ceccato DA. Determinação da concentração de formaldeído em alisantes capilares e comparação com a legislação vigente para efeitos de prevenção de intoxicação de usuários. In: XVIII Encontro de Ensino, Pesquisa e Extensão. 2013. Presidente Prudente: Universidade do Oeste Paulista, 2013.

15. Moro J, Claudino T, Deuschle R, Deuschle V, Fritz F, Hansen D, Bortolotto J, Paim C. Avaliação qualitativa e quantitativa de formaldeído em produtos cosméticos para alisamento capilar. In: XVIII Seminário Interinstitucional de Ensino, Pesquisa e Extensão. 2013. Cruz Alta: Universidade de Cruz Alta.

16. Santa Bárbara MC, Miyamaru LL. Resultado das análises de alisantes capilares. Bol. Epidemiol. Paul., São Paulo, 2008. 5(54):9-12.

17. Scarabelot JF, Michels, ML. Validação de metodologia para análise e investigação de formol em amostras de produtos usados em alisamento de cabelos. In: XVI Encontro de Química da Região Sul. 2008. Blumenau: Universidade do Sul de Santa Catarina.

18. Silva GL, Prete MC, Galão OF. Determinação de formol em amostras de produtos de alisamento capilar. Rev. Ciênc. Exat. e Tecnol., Londrina, 2013. 34(2):167-170.

19. Souza A, Watanabe CSF, Carrion, RCE. Avaliação físico-química de alisantes capilares utilizados pela população e suas implicações na saúde. In: 10. Fórum de Extensão e Cultura. 2012. Maringá: Universidade Estadual de Maringá.
20. Souza EM, Simões AMBM. A utilização de formol em alisantes capilares. In: 2. Congresso Norte Nordeste de Química. 2008. João Pessoa: Centro Federal de Educação Tecnológica da Paraíba.

21. BRASIL. Ministério da Saúde. Agência Nacional de Vigilância Sanitária. Guia de controle de qualidade de produtos cosméticos. Ensaios químicos e físicos. Brasília, 2008.

22. BRASIL. Portaria N. ${ }^{\circ}$ 503/94 de 6 de Julho de 1994. Estabelece os métodos de amostragem e de análise necessários ao controlo oficial da composição dos produtos cosméticos e de higiene corporal. Detalha, em documento anexo, os métodos de análise a implementar para garantia da qualidade destes produtos. Diário da República N. ${ }^{\circ} 154$ de 6 de Julho de 1994, I Série-B, p. 3567-3597.

23. Mendonça E. Tecnologia por trás dos cabelos dos sonhos. Rev. Household \& Cosméticos. São Paulo, 2011. 11(68).

24. BRASIL. Agência Nacional de Vigilância Sanitária. Resolução RDC n 4, de 30 de janeiro de 2014. Dispões sobre os requisitos técnicos para a regularização de produtos de higiene pessoal, cosméticos e perfumes e dá outras providências. Diário Oficial da União. Brasília, 31 jan. 2014.

25. Méndez TR. Efectos tóxicos crónicos del formaldehido. Rev. Facultad Med. Venezuela, 2003. 9(4):45-56.

26. Monakhova YB, Kuballa T, Mildau G, Kratz E, Keck-Wilhelm A, Tschiersch C, Lachenmeier DW. Formaldehyde in hair straightening products: Rapid H NMR determination and risk assessment. Intern. J Cosmetic Sci. 2013. 35:201-206.

27. Cavalcante T. Formol atinge cabeleireiras. Correio Braziliense, 12 abr. 2007. Disponível em: http://www.anvisa.gov.br/divulga/imprensa/clipping/2007/abril/120407. Acesso em 16 de dezembro de 2014.

28. Macagnan KK, Sartori MRK, Castro FG de. Sinais e sintomas da toxicidade do formaldeído em usuários de produtos alisantes capilares. Cad. Escola da Saúde. Curitiba, 2011. 1(4):46-63. 